\title{
Uma teoria histórico-materialista da retórica
}

\section{James Arnt Aune}

In Memoriam (1953-2013). Foi docente do Departamento de Comunicação da Texas A\&M University e membro vitalício da Rhetoric Society of America, Estados Unidos da América.

Resumo: O objetivo deste ensaio é desenvolver uma teoria retórica da ideologia que possa fornecer um paradigma unificador para a análise da comunicação pública, da teoria retórica e da tecnologia de comunicação. Antes, irei discutir o conceito de ideologia no marxismo clássico e o papel da teoria da hegemonia de Gramsci na resolução de alguns problemas no conceito clássico. E, em seguida, irei propor um modelo de retórica concernente ao seu papel na mediação da estrutura e da ação.

Palavras-chave: Retórica Crítica. Materialismo histórico. McGee. Ideologia. Hegemonia.

Abstract: The purpose of this essay is to develop a rhetorical theory of ideology that can provide a unifying paradigm for the analysis of public address, rhetorical theory, and communication technology. I will first discuss the concept of ideology in classical Marxism, and the role of Gramsci's theory of hegemony in resolving some problems in the classical concept. I will then propose a model of rhetoric in terms of its role in mediating structure and action.

Keywords: Critical Rhetoric. Historical materialism. McGee. Ideology. Hegemony.

\footnotetext{
'A Revista EID\&A agradece vivamente a Md Abu Naser, editor do American Communication Journal, pela autorização da publicação desta tradução do artigo: AUNE, James Arnt. An Historical Materialist Theory of Rhetoric. American Communication Journal, v. 6, n. 4, p. 1-20, 2003.
} 


\section{Introdução}

Em seu primeiro importante ensaio, “In search of 'the people': a rhetorical alternative" [“Em busca do 'povo': uma alternativa retórica”], Michael Calvin McGee (1975, p. 235) afirmou: "Embora preocupado quase exclusivamente com a vida pública e social, os estudantes de retórica não têm se envolvido muito com os tópicos da teoria social”. No final desse ensaio, ele convocou os estudantes de retórica "para participar dos sérios diálogos hegelianos e marxistas dos dois últimos séculos que afetaram muito a vida em nosso tempo".

Escrito numa época em que a teoria retórica e os estudos sobre comunicação pública pareciam estar em declínio, o trabalho de McGee estimulou alguns dos desenvolvimentos mais importantes nesse campo: 1) o desenvolvimento de estudos mais inteirados sobre oratória política teoricamente e outras formas de comunicação pública; 2) o desenvolvimento de abordagens "macro" para o estudo do discurso político ao longo do tempo; 3) interesse interdisciplinar na retórica em todas as ciências humanas, particularmente nas ciências políticas, na economia e na sociologia; 4) o surgimento de estudos crítico-humanistas da comunicação de massa; e, por fim, 5) a legitimação de saberes politicamente comprometidos com a esquerda.

Mas, por uma série de razões - a adoção, em grande parte acrítica, do pós-estruturalismo por estudiosos americanos, o prestígio da rejeição de Foucault ao marxismo e sua recusa anarco-libertária em se engajar na política convencional, a pós-moderna falta de interesse na história -, a convocação de McGee para um engajamento sério a Hegel e Marx caiu, em grande parte, em ouvidos surdos. Assim, o ensaio que se segue é minha tentativa de descrever uma teoria materialista histórica da retórica. Cada aspecto deste trabalho nasceu de conversas e de discussões sólidas com McGee, principalmente no outono de 1981 na Universidade da Virgínia e no verão de 1986 na Universidade de lowa.

Como McGee viu claramente, afirmar a possibilidade de estudos retóricos é criticar uma acentuada divisão de visões culturais que caracterizam tanto a modernidade quanto a pós-modernidade. A divisão é entre uma visão de mundo científica ou tecnológica relutante em se engajar em questões de 
ética e de valor e uma cosmovisão romântica em que a ênfase na autoexpressão individual parece minar a possibilidade da fala pública racional. Falar de retórica significa preservar a memória de momentos históricos em que, como Terry Eagleton (1990, p. 366) coloca:

[...] as três grandes questões da filosofia - $\mathrm{O}$ que podemos saber? O que devemos fazer? O que achamos atraente? - ainda não eram totalmente distinguíveis uma da outra. Uma sociedade, isto é, na qual as três poderosas regiões do cognitivo, do ético-político e do estético-libidinal ainda estavam em grande medida entrelaçadas.

Uma teoria materialista histórica da retórica deve, no entanto, primeiramente, reconhecer que o chamado "declínio" da retórica foi o produto de mudanças no modo de produção.

As muitas vezes incompreendidas tiradas de McGee contra o legado dos "gregos mortos" devem ser ajustadas diretamente ao contexto da mudança econômica e tecnológica. Novas tecnologias de comunicação (inicialmente, a imprensa; posteriormente, a rádio e a teledifusão) diminuíram os custos da informação, bem como o prestígio cultural do orador. O capitalismo aumentou a mobilidade ascendente e corroeu a cultura de deferência da qual a oratória tradicional dependia. A tradição clássica, no seu auge, pediu a seu auditório que se deslocasse da posição de súdito para a de cidadão. Mas o liberalismo inevitavelmente permitiu que o mercado superasse a participação democrática. Uma compreensão prática e acadêmica da dinâmica da cidadania e da liderança política nas democracias modernas e nas ditaduras exigiria uma compreensão materialista de como funciona o discurso como poder. Uma teoria materialista da retórica, sustentou McGee, precisa abranger o conceito de "ideologia".

O objetivo deste ensaio é, portanto, desenvolver uma teoria retórica da ideologia que possa fornecer um paradigma unificador para a análise da comunicação pública, da teoria retórica e da tecnologia de comunicação. Antes, irei discutir o conceito de ideologia no marxismo clássico e o papel da teoria da hegemonia de Gramsci na resolução de alguns problemas desse conceito clássico. Em seguida, irei propor um modelo de retórica nos termos de seu papel na mediação entre a estrutura e a ação. 


\section{A ideologia, segundo Marx e Engels}

No sentido marxista clássico, a ideologia é um discurso falso ou ilusório sobre o mundo e os seres humanos que o habitam. A grande contribuição de Marx para as ciências sociais é que ele não se contenta em mostrar que o discurso equivocado é logicamente ou referencialmente falso. Ele também quer explicar como esse discurso equivocado surgiu.

Como Jon Elster (1985) escreve, o discurso falso pode ser explicado tendo em vista a posição ou o interesse de um orador. Uma explicação relacionada à posição situa o discurso falso em equívocos cognitivos cometidos por um orador por causa de uma incapacidade de ver o todo de um fenômeno. Se eu falsamente declaro que o Sol se move ao redor da Terra, é porque eu não fui educado para sair da minha limitada posição de observação. Se eu acredito que todas as mulheres protegidas pela assistência social são afro-americanas, têm 10 filhos e abusam de nossos impostos, eu estou equivocado em razão de onde moro e de como fui educado.

A primeira discussão sobre ideologia em Marx e Engels usa uma metáfora óptica para ilustrar as distorções posicionais:

\footnotetext{
Se, em toda a ideologia, os homens e suas relações aparecem invertidos como em uma câmara obscura, este fenômeno decorre de seu processo de vida histórico, assim como a inversão dos objetos ao se projetarem sobre a retina decorre de seu processo de vida físico (MARX; ENGELS, 1975, p. 36).
}

A ideologia também emerge de uma posição social: "Todo mundo acredita que seu ofício seja o único e verdadeiro. Ilusões a respeito da relação entre o seu ofício e a realidade são as mais propensas de serem valorizadas devido à própria natureza do ofício" (MARX; ENGELS, 1975, p. 92). A falha cognitiva pode ser causada pelo interesse próprio, pelo desejo ilusório e pelo treinamento unilateral associado a uma ocupação particular. De fato, grande parte da crítica ideológica de Marx e Engels foi dirigida, primeiro, contra os economistas burgueses e, segundo, contra os autodenominados acadêmicos radicais, sendo que nenhum deles reconheceu as limitações da sua posição social.

Uma última forma de explicação relacionada à posição é a falha cognitiva que pode ser atribuída às necessidades de compensar uma realidade miserável. A denúncia da religião como o "ópio do povo" se enquadra nessa 
categoria. O falso discurso religioso ocorre como o resultado de uma falha cognitiva reforçada pela necessidade interna de consolo em um "mundo sem coração”. Às vezes, porém, Marx e Engels usavam uma noção diferente de ideologia - explicação associada ao interesse. Nessa perspectiva, as ideologias expressam, de modo transparente, os interesses econômicos e ocupacionais de uma pessoa:

As ideias da classe dominante são, em cada época, as ideias dominantes, isto é, a classe que é a força material dominante da sociedade é, ao mesmo tempo, sua força intelectual dominante. A classe que tem os meios de produção material à sua disposição, consequentemente também controla os meios de produção mental, de modo que as ideias daqueles aos quais faltam os meios de produção mental estão em todo o assunto para isto. (MARX; ENGELS, 1975, p. 59)

Esta passagem é uma das grandes fontes de problemas para o marxismo. Primeiramente, como argumenta Elster (1985), ela não explica como as ideias da classe dominante chegam a ser as ideias dominantes. Segundo, ela deixa de explicar como as ideias opositoras são ouvidas. Terceiro, as "ideias" são concebidas simplesmente como condutores de interesses, e não como espaços complexos de luta pelo sentido. A falha do marxismo em desenvolver uma teoria adequada de persuasão e liderança política dificultou uma compreensão completa da ideologia.

O desenvolvimento de estudos culturais dependeu em grande parte de fustigar o espantalho da explicação relativa ao interesse. Embora tal explicação tenha apenas um valor limitado na interpretação de objetos culturais, da pintura impressionista à música popular, é praticamente impossível entender as tendências políticas e econômicas atuais sem o conceito de explicação de interesse. Escritores de países social-democratas, como a Noruega ou a Grã-Bretanha, tendem a subestimar tal explicação. Nos Estados Unidos, a relação entre riqueza e poder político é frequentemente exposta de forma muito mais nítida.

Um dos mais importantes estudos publicados recentemente na esquerda é o relatório "Mobilizando uma Agenda de Política Pública: A Filantropia Estratégica das Fundações Conservadoras", publicado pelo National Center for Responsive Philanthropy [Centro Nacional de Filantropia Responsiva] em julho de 1997. Doze fundações, incluindo as fundações Olin e 
Scaife, contribuíram com US\$ 210 milhões, de 1994 a 1997 apenas, para promover as seguintes ações:

g) Criar programas acadêmicos conservadores: a Universidade de Chicago, Harvard, George Mason, Yale e Claremont McKenna foram os principais destinatários.

h) Apoiar think tanks regionais e think tanks sediados em Washington que coordenam suas agendas políticas. Mais recentemente, os think tanks vêm promovendo uma mensagem unificada sobre vales educacionais $^{1}$ e sobre a entrega de programas de bem-estar social para as igrejas do centro da cidade.

i) Pagar “intelectuais públicos”. Dinesh D’Souza recebeu uma bolsa de estudos do American Enterprise Institute no valor de US\$ 483.023,00, e Robert Bork ganhou US\$ 459.777,00 da Heritage Foundation.

j) Pagar estudantes para ter aulas de Direito e Economia, cursos que inevitavelmente promovem uma linha partidária sobre o papel dos mercados na resolução de todos os problemas sociais.

Como argumentei em outro artigo (Aune, 2001), essa promoção sistemática do "economicamente correto" não recebeu muita cobertura da imprensa, especialmente em comparação com a campanha cuidadosamente orquestrada contra o politicamente correto, financiada pelas mesmas fundações.

A "ideologia", do ponto de vista materialista histórico, assume, portanto, a forma de falácias sociais: perspectiva social limitada, "psicose ocupacional", prostituição intelectual e superstição. Um esclarecimento de como as ideologias se desenvolvem foi apresentado pelo escritor italiano Antonio Gramsci.

\footnotetext{
${ }^{1}$ N.T.: Segundo Jonathan Gruber, em seu livro Public Finance and Public Policy, de 2009, um vale educacional [educational voucher] é "uma quantia fixa de dinheiro dada pelo governo a famílias com crianças em idade escolar, que podem gastá-lo em qualquer tipo de escola, pública ou privada" (p. G-4).
} 


\section{A hegemonia, segundo Gramsci}

A primeira intuição de Gramsci foi reconhecer que a Revolução no Ocidente não ocorreria por meio de uma guerra de movimento, ou ataque frontal, como na Rússia czarista. Ao contrário, ocorreria por meio de uma guerra de posição, ou guerra de trincheiras, em que intelectuais desempenhariam um papel diferente do assumido no partido de vanguarda de Lenin. Os Cadernos do Cárcere de Gramsci centram-se no problema da função política dos intelectuais. Todas as pessoas têm um instinto filosófico, mas este instinto é bem mais desenvolvido entre os intelectuais do que em outros. $O$ problema com os intelectuais, no entanto, como Gramsci escreve, é que eles sabem, mas nem sempre entendem e, em particular, nem sempre sentem. Em contraste, o “elemento popular 'sente', mas nem sempre sabe ou compreende" (GRAMSCI, 1977, p. 418).

Os intelectuais podem ser divididos em dois grupos: os intelectuais orgânicos, que são necessários para qualquer nova classe que procura desenvolver uma nova ordem social; e os intelectuais tradicionais, que estão ligados a um período histórico anterior. Ambos os grupos de intelectuais ajudam a construir uma unidade sociocultural ("hegemonia") que forma a base de um "bloco histórico". A história, para Gramsci, é uma sucessão de blocos históricos criados pela prática política e não meramente por uma sucessão de modos de produção. Um bloco histórico representa uma unificação de vários grupos com diferentes interesses que, não obstante, chegam a uma unidade sociocultural sob a liderança do Partido. O partido tem, assim, uma função comunicativo-cultural e uma função antecipatória: é uma instituição autônoma na qual se pratica a genuína igualdade democrática.

Na recente teoria cultural que invoca Gramsci, o papel do Partido como o “moderno Príncipe" (1977, p. 133) atrofiou-se, o que levou à visão generalizada de que qualquer coisa que lide com "relações de poder" é, de alguma forma, "política”, uma definição que parece descartar os tipos reais de política em que Gramsci estava interessado.

Para melhor utilizar a noção de hegemonia de Gramsci, é útil estabelecer um contínuo de dominação. Suponhamos por um momento que um grupo em particular detenha o poder. Eles não detêm o poder por qualquer razão legítima; na verdade, eles provavelmente detêm poder por causa de injustiças 
passadas. A vida seria melhor se eles não mantivessem o poder, pelo menos para os oprimidos. Como eles mantêm o poder, mesmo quando um observador objetivo pode ver tanto a injustiça da situação quanto as oportunidades substanciais para o grupo oprimido se revoltar?

Primeiro, o grupo dominante pode empregar a coerção ou a ameaça de coerção para exigir obediência. Essa estratégia possui benefícios a curto prazo, mas problemas a longo prazo, porque requer constante vigilância e porque o grupo dominado pode não produzir o que o grupo dominante precisa com a mesma eficiência sob condições de monitoramento constante.

Em segundo lugar, o grupo dominante pode exercer controle rígido sobre as informações de posse do grupo dominado ou até promover ativamente uma "falsa consciência" entre esse mesmo grupo por meio das instituições que ele controla ativamente. A situação de um trabalhador de uma fábrica têxtil, por volta de 1920, se encaixaria nessa estratégia. O trabalhador depende inteiramente do proprietário da fábrica para sua alimentação e abrigo e até para necessidades educacionais e religiosas. Quaisquer tentativas de obter informações externas são rigorosamente reprimidas. Essa estratégia, no entanto, tem valor limitado em uma sociedade com grupos de interesses diversos (e controles social-democratas do poder capitalista) e maior mobilidade geográfica. Contudo, a mobilização em curso, encabeçada pela Comissão Federal de Comunicações, para desregulamentar a propriedade dos órgãos de comunicação social ameaça criar um monopólio da informação. Explicações ideológicas baseadas em interesse talvez sejam agora mais plausíveis nos EUA do que em qualquer época desde o New Deal².

Terceiro, o grupo dominante pode exercer um controle mais sutil sobre o "senso comum" de um povo inteiro, recorrendo a intelectuais para representar o status quo de forma que o façam parecer inevitável e necessário. Fontes de informação dominantes e de apelos motivacionais "naturalizarão" a ordem social, às vezes até dentro de limites notavelmente amplos, em um processo que resulta na aceitação dos dominados acerca da inevitabilidade de as coisas estarem como estão. Os sucessos da política econômica da direita desde 1975 podem levar um observador a pensar que na

\footnotetext{
${ }^{2}$ N.T.: New Deal [Novo Acordo] foi o nome dado aos programas socioeconômicos implementados durante o governo de Franklin Roosevelt (1933-1937), para recuperar a economia estadunidense após a crise de 1929.
} 
verdade tem sido apenas a direita que lê Gramsci. No entanto, devido à maior mobilidade e pluralismo, o grupo dominante não pode controlar as coisas completamente e é tão vulnerável à falha cognitiva e ao desejo ilusório quanto os outros grupos. Sem uma análise econômica, uma abordagem puramente comunicativa da hegemonia poderia perder de vista a inerente instabilidade da ordem capitalista em si. O grupo dominante não somente irá se dividir, em termos de interesse regional, como também irá agir continuamente de acordo com a falácia da composição: o que é bom para uma empresa é bom para todos. A pressão da tecnologia sobre o emprego, a subversão da ética do trabalho por meio do consumo e a concorrência implacável tenderão a criar resistência em grupos subalternos e também a reduzir a rentabilidade. E, adicionada a degradação ambiental nesse conjunto, tem-se, em última instância, um grupo dominante eliminando a si mesmo e seus mercados.

Uma explicação gramsciana do Reaganismo, por exemplo, é que ele ajudou a promover uma visão de senso comum que toma o mercado como mais eficiente e moral do que o governo. A defesa reaganista do mercado, no entanto, ocorreu por meio da mobilização de apelos nacionalistas à glória militar. Na ausência de uma ameaça comunista, apelos ao mercado perderam sua popularidade; o que resta é uma hostilidade generalizada ao governo como um todo e também à globalização da economia. Como os neoconservadores da revista The Weekly Standard reconheceram, não se pode construir um momento conservador simplesmente pela oposição ao governo, por conseguinte, eles apelaram ao exemplo de Teddy Roosevelt por um novo espírito de ativismo global e governamental de direita. A atual fragmentação da direita entre conservadores sociais cristãos, libertarianistas, nacionalistas paleoconservadores econômicos e republicanos de tradicionais clubes de campo [country club] continuará até uma nova ideologia ser elaborada. Os libertarianistas e os paleoconservadores desertaram do esforço de George W. Bush para criar um novo consenso conservador em nome do combate ao terrorismo. Resta saber se os dezenove milhões de cristãos eleitores de direita, que são a base política mais forte de Bush, serão suficientes para sustentar sua reeleição, especialmente com o apoio de Bush à criação de um Estado palestino.

A teorização de um momento positivo de hegemonia permanece limitada, provavelmente por causa de um negativismo aparentemente 
congênito entre os esquerdistas ocidentais desde a Segunda Guerra. Gramsci faz uma defesa inspiradora da importância da educação e do papel do partido como o lugar onde os novos modos democráticos de consciência podem ser desenvolvidos. Gramsci também especificou o tipo de coisas que o partido deve dizer na construção de unidade sociocultural. O partido deve apoiar-se na unidade moral de uma ordem social, expressa em formas populares por símbolos representativos, mitos e sabedoria folclórica, devendo guiar essa unidade moral para um novo e mais sofisticado nível. Gramsci, ele próprio de origem incomumente humilde para um intelectual marxista, claramente não acreditava que o capitalismo tivesse arruinado a sabedoria do povo, como também não arruinara a herança da cultura ocidental. Gramsci considerava o marxismo como a síntese mais recente da tradição ocidental no seu auge, pressupondo, em suas palavras, "o Renascimento e a Reforma, o idealismo alemão e a Revolução Francesa, o calvinismo e a economia clássica inglesa, o liberalismo secular e esse historicismo que está na raiz de toda a concepção moderna de vida" (GRAMSCI, 1977, p. 395). Como Terry Eagleton destacou recentemente, os marxistas sempre viveram na tradição; somente os capitalistas pensam que podem viver sem isso.

O partido como uma forma de "democracia antecipatória", a importância da cultura e da comunicação popular, o papel político dos intelectuais e a noção de bloco histórico consistem nas contribuições de Gramsci para uma teoria e para uma prática política emancipatória. Gramsci ensinou que "o saber nunca é uma reflexão passiva sobre o que é dado, mas um ato criador das mediações necessárias para direcionar a vida" (PICCONE, 1983, p. 196-197). Uma dessas mediações necessárias é a arte da retórica, à qual me volto agora.

\section{Uma Teoria da Retórica e da Comunicação Pública}

O desenvolvimento da teoria retórica neste século nos ajudou a fazer perguntas sobre como auditório, figuração, narrativa e estratégia interagem no discurso prático. Uma dimensão não examinada da teoria retórica, no entanto, é o papel da dialética e da "contradição" na prática da advocacia. Até mesmo McGee e seus estudantes demonstraram pouco interesse no tradicional trabalho hegeliano e marxista sobre a dialética. 
Uma contradição é bem definida como uma oposição que é, ao mesmo tempo, necessária e destrutiva a um processo particular. Todo processo social apresenta tendências contraditórias. A compreensão de Marx sobre o capitalismo foi que a sua própria necessidade de crescimento contém tendências de autonegação, sendo que as duas principais são a rivalidade inerente entre as empresas capitalistas e o impulso para mecanizar a produção.

O que não estava claro no marxismo, porém, era a consciência de seu próprio caráter dialético. Se todos os processos sociais têm tendências contraditórias e se os seres humanos são forçados (seja pelo Espírito Absoluto ou, mais provavelmente, pela necessidade de manter o equilíbrio psicológico) a buscar unidade na contradição, então o próprio marxismo também deve ter contradições e unidades construídas.

Com a contradição vem a necessidade da mediação. O conceito surge, inicialmente, nas reflexões de Hegel sobre cristologia. O problema da alienação, que aparece aqui como o fosso entre o finito e o infinito, é mediado pela identificação com a figura de Jesus, que descobre Deus dentro de si e supera a alienação com uma vida de amor abnegado.

O tema da reconciliação aparece em uma escala cósmica no conceito de Espírito Absoluto. Para Hegel, todas as coisas são mediadas, isto é, elas se relacionam a todas as outras coisas e ao Todo. O Absoluto é o processo de a realidade vir a conhecer a si mesma. A realidade vem a conhecer-se no e por meio do espírito humano. A forma determinada assumida pelo Absoluto na história é o espírito nacional.

Marx desmitificou a noção hegeliana de mediação (embora sua negligência do papel do nacionalismo como uma poderosa força mediadora voltaria a assombrar o marxismo no século XX). Para Marx, o trabalho faz a mediação entre a natureza e os seres humanos. A atividade produtiva do ser natural automediador é a principal condição para a autoconstituição humana, a base ética do pensamento de Marx. Esta automediação, no entanto, é bloqueada por formas historicamente específicas de mediação de segunda ordem, como o dinheiro, a troca e a propriedade privada. O "segredo do fetichismo da mercadoria" é explicado pelo fato de que, sob o capitalismo, a produção do valor de uso é mediada pela e subordinada à produção do valor 
de troca. Como disse Habermas (1991, p. 32), o problema com o capitalismo é que ele se cega a tudo que não possa ser expresso na forma de um preço. Por fim, a mediação é também mediação entre teoria e prática, realizada pela atividade prática.

O conceito de mediação aparece, então, quando existe uma divisão seja entre a teoria e a prática, seja entre o ideal e o real. Embora Kenneth Burke nunca tenha lidado com o conceito de mediação de Hegel ou de Marx, sua discussão sobre identificação em seu livro A Rhetoric of Motives [Uma retórica de motivos] fornece algumas possibilidades interessantes para "mediar" os conceitos de retórica e mediação.

Assim como Hegel proclama que a divisão é o ponto de partida da filosofia, Burke escreve:

A identificação é afirmada com seriedade exatamente porque existe divisão. A identificação é compensatória para a divisão. Se os homens não estivessem separados uns dos outros, não haveria necessidade de o retor proclamar sua unidade. Se os homens fossem total e verdadeiramente de uma única substância, a comunicação absoluta seria da própria essência do homem. Não seria um ideal, como é agora, parcialmente incorporado às condições materiais e parcialmente frustrado por essas mesmas condições; ao contrário, seria tão natural, espontâneo e completo à semelhança dos protótipos ideais de comunicação, os anjos do teólogo ou "mensageiros". (BURKE, 1969, p. 22)

O estudo da retórica é, então, o estudo do reino da divisão. A prática da retórica envolve a construção de identificações, elas mesmas enraizadas nas propriedades (e propriedade) de pessoas, grupos e objetos. A identificação, como escreve Burke, pode funcionar por meio da identificação estilística, da identificação dos interesses do auditório com os interesses do orador (uma identificação sujeita a mistificações do termo "propriedade"), ou da extensão metafórica da relação pai-filho descrita pelas noções freudianas de identificação e transferência. Transferência significa tratar o outro como uma metáfora.

É a presença de um auditório e de um oponente (na forma de uma política rival, de uma pessoa ou de uma cultura) que sinaliza a existência de uma "situação retórica". A presença de oposição implica uma ligação entre a retórica e a dialética no sentido hegeliano. Há certos pontos previsíveis em qualquer controvérsia a partir da qual a argumentação acontecerá. Os teóricos clássicos chamavam isso de estase [stasis]. Qualquer debatedor sobre 
política pública sabe que certas questões fundamentais sobre a existência de um dano, quem é o culpado por ele, como resolvê-lo e quanto custa a persistência desse dano aparecerão reiteradamente. Um advogado sabe que as questões de fato, definição, qualidade e jurisdição ocorrerão em qualquer caso legal.

Um caso persuasivo deve aprender a incorporar objeções com base nas estases inerentes ao campo da argumentação em que ocorre a controvérsia. Algumas objeções, no entanto, derivam da natureza da controvérsia em si, e essas objeções são dialéticas.

A própria prática retórica baseia-se na contradição fundamental de que o advogado deve parecer não estar tão envolvido em um ato de persuasão quanto em ajudar o auditório a descobrir o que já sabe. O advogado e o auditório também podem se tornar tão autoconscientes da retórica como uma performance que a retórica pode se tornar um substituto para a ação. Existem outros pontos fundamentais na maioria das controvérsias em que tendências de autonegação aparecem na prática retórica.

Primeiro, a fim de esclarecer um argumento a um público, um advogado deve inevitavelmente simplificá-lo. Este ato de simplificação sujeita o advogado a acusações de reducionismo.

Segundo, outro tipo de exagero ocorre quando uma pessoa, grupo ou sistema em oposição é necessariamente descrito como poderoso e mal. O advogado pode ser acusado de ser injusto ou de promover um senso de futilidade ou "vitimização". O julgamento retórico nesses casos envolve encontrar a média entre uma abordagem benevolente do opositor e uma descrição que o construa como todo-poderoso.

Terceiro, a fim de antecipar acusações de reducionismo, simplificação excessiva ou supergeneralização, um advogado pode ter de qualificar alegações e sua aplicabilidade geral, conduzindo, assim, o auditório a um déficit motivacional. Em outras palavras, o ódio do público e a vontade de agir são mais facilmente despertados por caracterizações simplistas do inimigo, mas o desejo de ser democrático, liberal e autorreflexivo incute hábitos de pensamento que limitam a capacidade de motivar públicos. O esforço para apresentar um caso a um "auditório universal" idealmente racional pode tender a limitar a adaptabilidade a auditórios particulares. 
Em termos mais clássicos, a divisão entre orador e auditório é mediada por estratégias que unem uma ação proposta aos valores aceitos, às crenças, aos objetivos do auditório e sua cultura (logos); estratégias que unem a ação e a disposição desse auditório (pathos); e estratégias que fazem do orador um representante digno de fé das aspirações do auditório (ethos). Os aspectos de autonegação das práticas sociais tornam a função mediadora e sintetizadora da prática retórica essencial para o florescimento humano.

$\mathrm{Na}$ medida em que a divisão ou a alienação tem sido uma característica constante das sociedades humanas, o impulso retórico parece ser um desenvolvimento natural de outros mecanismos de enfrentamento, como a magia e o ritual. A forma específica de divisão nas sociedades modernas consiste em um efeito da industrialização, da divisão do trabalho e da extensão do mercado em todas as esferas da prática humana. Há razões muito concretas para afirmarmos que somos todos marxistas hoje. Neoconservadores e socialistas conservadores, como William Bennett (1994) ou Daniel Bell (1976), argumentam que a cultura tradicional desempenha um papel essencial em proteger indivíduos e famílias das forças desestabilizadoras do mercado. Os liberais clássicos do direito, da economia e da teoria da escolha pública, bem como libertarianistas em geral, reduzem toda a motivação humana ao cálculo econômico, diferindo do Marxismo apenas em seu programa político: dispersar o poder econômico tanto quanto possível até que surja uma ordem natural.

O problema da divisão na sociedade capitalista pode ser esclarecido por meio dos trabalhos dos sociólogos Erik Olin Wright (1985) e Anthony Giddens (1979). Wright argumentou que debates metodológicos no marxismo tendem a responder a esse fato, alegando que Marx e Engels estavam fazendo duas coisas muito diferentes: fornecendo um mapa estrutural abstrato das relações de classe no Capital e fornecendo mapas conjunturais concretos de classes como atores nos escritos políticos e históricos. Embora Marx tenha previsto que, com o decorrer do tempo, haveria uma convergência cada vez maior entre a análise de classes abstrata e concreta (algo que agora parece estar acontecendo com a globalização do capitalismo), existem ainda diferentes níveis de abstração que precisam ser considerados na análise marxista. 
A partir do trabalho de Wright, podemos imaginar uma determinada totalidade social situada em um dado momento dispostos, verticalmente, em duas partes, estrutura de classe e formação de classe, e, horizontalmente, em três partes: (1) o modo de produção, nível de análise mais alto ou mais abstrato; o modo de produção capitalista, por exemplo, é composto por duas principais classes concorrentes, cuja luta define uma época específica; (2) a formação social, em que existem mais de duas classes primárias, e os agentes humanos podem estar ancorados simultaneamente em diferentes modos de produção e estágios de desenvolvimento; (3) finalmente, a conjuntura, que inclui fatores históricos contingentes.

Figura 1 - Níveis de análise social de Wright

\begin{tabular}{ccc}
\hline Nível de abstração & \multicolumn{2}{c}{ Objeto teórico de análise } \\
\hline MODO DE PRODUÇÃO & $\begin{array}{c}\text { Relações de classe } \\
\text { polarizadas } \\
\text { FORMAÇÃO SOCIAL }\end{array}$ & LoRMAÇÃO DE CLASSE \\
CONJUNTência de classes & $\begin{array}{c}\text { Alianças de classe baseadas } \\
\text { em diferentes modos de } \\
\text { produção }\end{array}$ \\
& $\begin{array}{c}\text { Variabilidade } \\
\text { institucional }\end{array}$ & $\begin{array}{c}\text { Organizações de classe } \\
\text { concretas: partidos, } \\
\text { sindicatos }\end{array}$ \\
\hline
\end{tabular}

Fonte: Adaptado a partir de Wright (1985, p. 9)

O que falta na análise de Wright é uma teoria de mediação entre estrutura de classes e formação de classes. Em outras palavras, como as instituições, as práticas e as mensagens moldam a formação de classes? Quais instituições, práticas e mensagens alternativas estão disponíveis para aqueles que desejam remodelar as formações de classe no quadro de possibilidades estruturais? Em Rhetoric and Marxism [Retórica e Marxismo] (Aune, 1994), defendi que essa lacuna não teorizada na análise de Wright está presente no marxismo clássico e que os teóricos posteriores tentaram preenchê-la com conceitos como o partido de vanguarda leninista, o socialismo evolucionário 
de Bernstein, ou mesmo "novas" classes, como os estudantes radicais de Marcuse ou os intelectuais de Gouldner.

Minha proposta, adaptada da noção de estruturação de Giddens, sustenta que as práticas comunicativas medeiam a estrutura e a luta. Essas práticas comunicativas podem ser analisadas nos três níveis de abstração de Wright.

No nível mais alto de abstração - o modo de produção -, entendemos que a tecnologia da comunicação define a natureza do tempo e do espaço para os atores sociais. Como Harold Innis (1951 apud Carey 2009, p. 122-123) argumenta, as tecnologias de comunicação manipulam o espaço ou o tempo, e o "viés" particular da comunicação no capitalismo tem sido a extensão do espaço em detrimento do tempo e da memória. Grande parte da luta de classes no capitalismo consistiu em uma luta pelo controle do próprio tempo, particularmente da duração do dia de trabalho. Um adesivo popular entre os sindicalistas diz: "O movimento trabalhista - as pessoas que Ihe trouxeram o fim de semana"3.

Atualmente, a luta de classes é cada vez mais definida em termos espaciais, à medida que o capital se torna cada vez mais móvel através das fronteiras nacionais. Muitas fontes de negócios proeminentes, incluindo a revista Forbes e Esther Dyson, têm argumentado abertamente que o próprio estado-nação está condenado graças à internet. Primeiro, fábricas e empregos tornaram-se gradativamente mais móveis. Agora, o próprio capital se tornou completamente móvel: "milhões de investidores comuns podem movimentar sua fortuna entre diferentes moedas e países tão rapidamente quanto puderem clicar nos ícones na tela" (HUBER, 1996). O resultado é que os governos estão se tornando incapazes de tributar, de modo que todos os esforços para fornecer um padrão mínimo de bem-estar tendem a evaporar se outro estado ou governo oferece uma taxa de imposto mais baixa.

$\mathrm{Na}$ ausência de controle democrático sobre as novas tecnologias, o futuro mantém a promessa de um sistema econômico laissez-faire mais brutal que os Dark Satanic Mills ${ }^{4}$ da Inglaterra do século XIX ou das maquiladoras de

\footnotetext{
${ }^{3}$ N.T.: No original, "The Labor Movement - the Folks Who Brought You the Weekend".

${ }^{4}$ N.T.: A expressão refere-se aos moinhos ou às fábricas britânicas do século XIX que impunham aos seus empregados condições de trabalho desumanas.
} 
hoje. O debate sobre pornografia na internet ilustra como as questões culturais ainda podem mascarar interesses econômicos; o real debate deveria ter sido sobre o impacto econômico das novas tecnologias, mas isso não aconteceu.

Além do tempo e do espaço tecnologicamente determinados, o nível de análise do modo de produção também considera o papel de instituições particulares, incluindo os meios de comunicação, na constituição de formas de deliberação pública que, por sua vez, definem a natureza da ação política. Trabalhos recentes sobre o papel dos jornais, das cafeterias e das tabernas no desenvolvimento de uma esfera pública do século XVIII são bons exemplos desse tipo de análise.

No nível da formação social e da conjuntura, encontramos a principal conquista dos estudos de retórica e de comunicação pública: esclarecer o papel da discussão pública na história americana ou britânica e fornecer sensibilidade a questões estratégicas em situações retóricas específicas. No nível da formação social, temos estudos “macro" de comunicação pública, como os de Lucaites e Condit (1990) ou de James Darsey (1997) em seu recente livro sobre o discurso profético. No nível da conjuntura, temos a análise textual detida e as tradicionais análises de estratégias e de efeitos. 0 vocabulário tradicional da retórica aristotélica e ciceroniana permanece útil para teorizar acerca da estratégia no nível conjuntural, ainda que a análise da prática retórica no nível da formação social tenha exigido o desenvolvimento de novo vocabulário.

O vocabulário que melhor capta a maneira pela qual "uma" retórica no nível da formação social medeia possibilidades estruturais e ação do auditório é a descrição de Lucaites e Condit (1990) do papel das caracterizações, narrativas e ideógrafos como dispositivos unificadores de estratégias de legitimação.

Caracterizações - por exemplo, "liberal do nordeste" ou "mamãe do futebol" -fornecem "o primeiro passo na transição da experiência material da vida cotidiana para a avaliação coletiva por meio do simples processo de fornecer nomes concretos, mas carregados de motivação, a entidades

\footnotetext{
${ }^{5}$ N.T.: Trata-se de expressão consolidada nos Estados Unidos (soccer mom) em referência a mulheres brancas, de classe média, suburbanas que disponibilizam grande parte de seu tempo transportando crianças em idade escolar para eventos esportivos, dentre outras atividades. Segundo a Wikipedia, a expressão se consolidou nas eleições presidenciais americanas de 1996.
} 
politicamente salientes" (LUCAITES; CONDIT, 1990, p. 7). As narrativas estruturam "as relações particulares entre as várias caracterizações; fornecem, portanto, um entendimento de como a realidade material se mantém e funciona" (p. 8). Ideógrafos, ou valores culturais ideais, são incorporados às narrativas como termos de finalidade principal. Os conservadores, por exemplo, contam uma história sobre a pobreza urbana na qual "liberais" [caracterização] criaram classes desfavorecidas por meio dos programas antipobreza dos anos 1960 [narrativa], que minaram a “autossuficiência” [ideógrafo].

O que Lucaites e Condit (1990) não conseguem teorizar, no entanto, é o princípio de movimentação ou de transformação em ideógrafos, narrativas e caracterizações. Em um nível simples, os imperativos ideológicos de dois ideógrafos aceitos podem entrar em conflito, como acontece entre "liberdade" e "igualdade", ou entre "comunidade" e "mercado". Em um nível mais complexo, é possível analisar a lógica semiótica que rege as relações entre ideologia e narrativa, ao mapear uma história como um sistema narrativo de personagens ou agentes que é, então, transformado em "um mecanismo de troca pelo qual pode ser gerada alguma ilusão final de harmonia, alguma solução 'imaginária' final da contradição que articula” (JAMESON, 1979, p. 99). Jameson recorre ao quadrado semiótico de Greimas para ilustrar as maneiras pelas quais as oposições fundamentais podem gerar sistemas narrativos. O quadrado semiótico é "a representação de uma oposição binária (dois contrários), juntamente com as simples negações (ou contraditórios) de ambos os termos (os chamados subcontrários) e o termo 'neutro' (síntese ideal de dois subcontrários)" (JAMESON, 1979, p. 99). Jameson utilizou o quadrado semiótico proficuamente para analisar narrativas fictícias, bem comoa sociologia de Max Weber.

Se tentássemos desenvolver um mapa retórico das filiações ideológicas atuais sobre a economia global e da tensão crescente entre os valores tradicionais e o livre mercado, poderíamos aplicar a intuição de Jameson do seguinte modo. O colapso da União Soviética redefiniu a oposição tradicional entre "liberdade" e "comunismo" numa revelação gritante da contradição fundamental que integra o modo de produção capitalista desde o início. A contradição entre os imperativos do Mercado e os requisitos para o florescimento humano, ou Comunidade, parece gerar o seguinte padrão: 


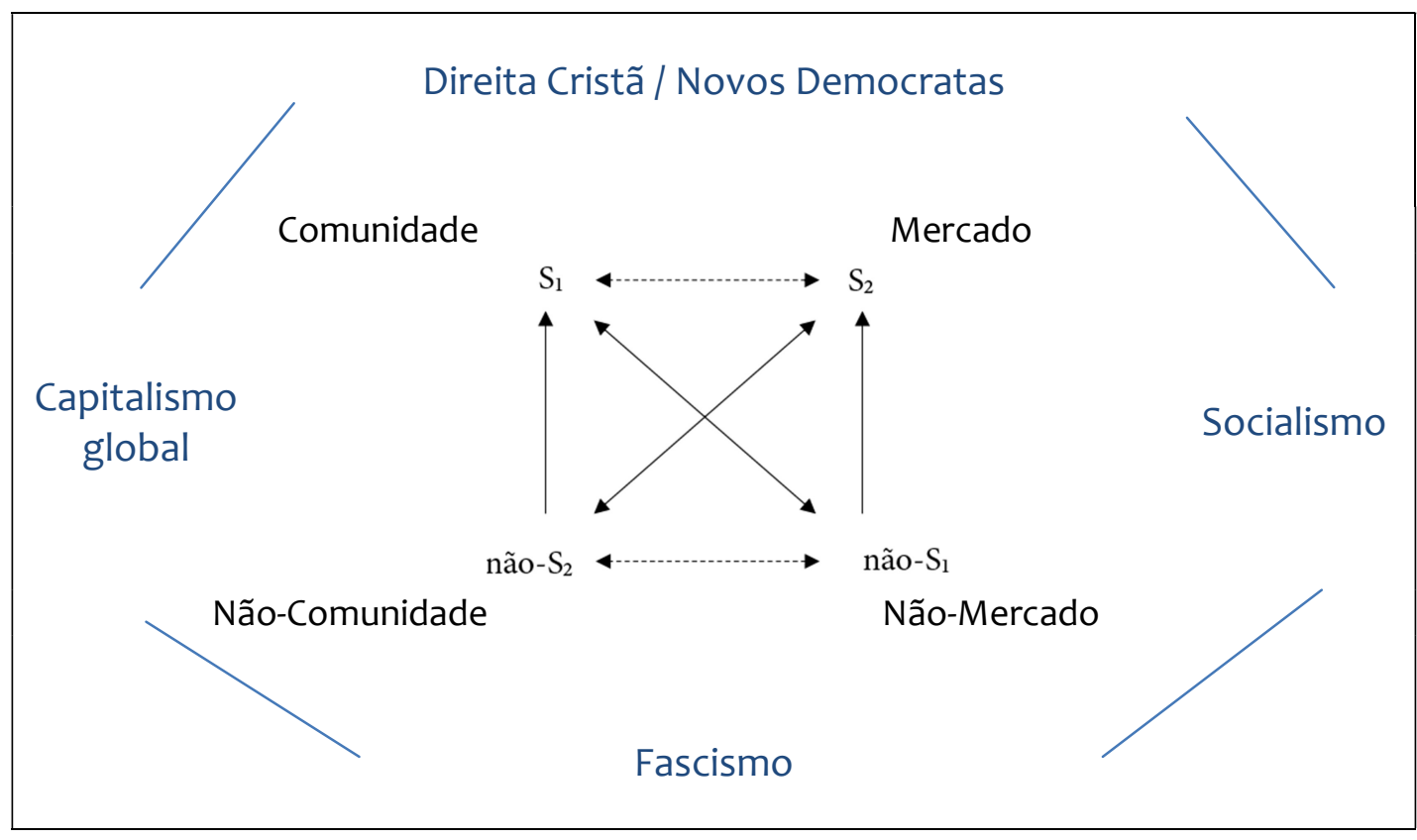

$\begin{array}{ll}\hookrightarrow & \text { Relação de contrariedade } \\ \longleftrightarrow & \text { Relação de contradição } \\ \longrightarrow & \text { Relação de complementaridade }\end{array}$

O conflito ideológico mais evidente na formação social americana contemporânea é entre os "Novos Democratas" de Clinton e a "Direita Cristã". O caráter peculiarmente carregado desse conflito, se minha análise estiver correta, pode estar em sua luta para ocupar o mesmo espaço semiótico dos mediadores do conflito Mercado-Comunidade, com os capitalistas globais, de um lado, e os socialistas, do outro, aguardando o momento em que o conflito declarado se resolva ou em que novas alianças sejam formadas. A mobilização bem-sucedida de um nacionalismo fanático na guerra contra o Iraque, promovida por Bush, ocupa o mesmo espaço semiótico, mas, a longo prazo, é provável que se perca diante de questões mais estritamente econômicas. O risco do fascismo como uma mediação alternativa do conflito entre Comunidade e Mercado seja talvez mais real do que em qualquer momento desde a II Guerra Mundial.

No nível conjuntural, encontramos o retor exercendo julgamento político na seleção de matérias-primas ideológicas a partir da característica retórica da formação social. Por exemplo, seguindo a análise de Bellah et al (1985), em Habits of the Heart, poderíamos afirmar que os americanos têm 
tradicionalmente argumentado com base em uma retórica primária de individualismo, complementado por retóricas secundárias de justiça bíblica e republicanismo. A combinação precisa desses apelos é determinada pelo retor, que também constrói seu próprio senso de autoridade cultural - ethos, a “primeira persona" -, um auditório preferido - a "segunda persona" de Black (1970) - e auditórios marginalizados - a "terceira persona” de Wander (1984).

Em suma, uma leitura retórica, no sentido mais pleno, de um corpo de textos requer uma análise das limitações estruturais dos "meios disponíveis de persuasão", limitações que, no nível mais abstrato, normalmente não estão dentro da consciência do defensor. Também requer uma compreensão das matérias-primas ideológicas elaboradas pelo retor, o que inclui narrativas, caracterizações, evidências e ideógrafos. Um texto ou corpo de textos forma assim uma constelação de elementos unidos pela força retórica inerente ao todo, como um momento mediador entre possibilidades estruturais e ação coletiva. Às vezes, um texto é costurado unicamente pela força do estilo ou do ethos do retor, ou pelo peso acumulado das evidências históricas que ele impõe ao auditório. Mas os textos são entidades instáveis. A presença de oponentes, assim como de fatores históricos estruturais e contingentes, fará com que momentos retóricos progridam, cresçam ou morram. Lê-se retoricamente para realizar dois propósitos complementares: avaliação do julgamento retórico em determinados casos e compreensão preditiva ou explicativa da movimentação de textos como blocos de construção de ideologias - de acordo com a movimentação dessas ideologias no tempo histórico. A figura 2 representa minha modificação do diagrama original de Wright (1985).

Figura 2 - Os níveis de conhecimento retórico

\begin{tabular}{|c|c|}
\hline Nível de abstração & Objeto teórico de análise \\
\hline MODO DE PRODUÇÃO & $\begin{array}{l}\text { Tecnologia de comunicação; construções do tempo e do } \\
\text { espaço; constituição de formas particulares de comunicação } \\
\text { e seu auditório }\end{array}$ \\
\hline FORMAÇÃO SOCIAL & $\begin{array}{l}\text { "Retóricas" primária e secundária, incluindo narrativas, } \\
\text { caracterizações e ideógrafos recorrentes }\end{array}$ \\
\hline CONJUNTURA & $\begin{array}{l}\text { Características contingentes de situações retóricas, incluindo } \\
\text { oponentes e recursos; julgamentos estratégico-particulares } \\
\text { realizados pelo retor; respostas do auditório e dos oponentes }\end{array}$ \\
\hline
\end{tabular}

Fonte: Elaboração própria 
As ações retóricas representam, assim, mediações entre estrutura e luta, mas elas também têm suas próprias tendências de autonegação, que envolvem simplificação, adaptação ao auditório, presença de oponentes e o diagnóstico de Burke sobre a tendência dos retores a se envolverem em teias de significação que eles mesmos fiam - particularmente a tendência de que, uma vez adotado, um determinado vocabulário busque sua própria "perfeição". A retórica de George Bush I contra Saddam Hussein tendia a buscar sua própria "perfeição" no conceito de "terminar o trabalho que começamos".

A retórica do mercado tende a invadir todas as esferas da vida, como se pode observar na proposta de Richard Posner (1992) de vender bebês para resolver os problemas de adoção e de aborto, algo que o Presidente Reagan provavelmente não tinha em mente quando nomeou Posner para $07^{\circ}$ Circuito.

\section{Conclusão}

Este ensaio visou a esclarecer minha abordagem sobre a crítica retórica à ideologia, reunindo temas da retórica clássica, da teoria retórica materialista de McGee, do marxismo gramsciano, de Fredric Jameson e de Kenneth Burke. Os temas centrais foram:

1) o papel da ideologia como distorção cognitiva, criada pelo posicionamento social e pelos interesses econômicos;

2) uma visão gramsciana de hegemonia como um processo político dirigido em parte pelo papel dos intelectuais na constituição do conhecimento e do senso comum;

3) uma visão da retórica como meio de resolver as contradições sociais, mediando, de forma geral, as estruturas sociais e as possibilidades para ação coletiva;

4) uma teoria das relações entre tecnologia da comunicação, retórica dominante e estratégia retórica em termos de um modelo marxista geral de modo de produção, formação social e conjuntura.

Mas a questão, como Marx (e McGee) apontou há muito tempo, não é apenas analisar o mundo, mas mudá-lo. Assim, apresento este ensaio em parte como um esforço para pagar a minha dívida de longa data a McGee, mas, em grande parte, para contribuir para a política emancipatória que ele defendia. 


\section{Referências}

AUNE, James Arnt. Rhetoric and Marxism. Boulder: Westview Press, 1994.

. Selling the Free Market: The Rhetoric of Economic Correctness. New York: Guilford Press, 2001.

BELL, Daniel. The Cultural Contradictions of Capitalism. New York: Free Press, 1976.

BELLAH, Robert N.; SWIDLER, Ann; MADSEN, Richard; TIPTON, Steven M.; SULLIVAN, William M. Habits of the Heart: Individualism and Commitment in American Life. Berkeley: University of California Press, 1985.

BENNETT, William J. The De-Valuing of America: The Fight for Our Culture and Our Children. Colorado Springs: Focus on the Family, 1994.

BLACK, Edwin. The second persona. Quarterly Journal of Speech, v. 56, p. 109-119, 2009 [1970]. DOI 10.1080/00335637009382992.

BURKE, Kenneth. A Rhetoric of Motives. Berkeley: University of California Press, 1969.

CAREY, James W. Space, Time, and Communications: A Tribute to Harold Innis. In: (Ed.). Communication as Culture: Essays on Media and Society. Revised edition. New York: Routledge, 2009.

DARSEY, James. The Prophetic Tradition and Radical Rhetoric in America. New York: New York University Press, 1997.

EAGLETON, Terry. The Ideology of the Aesthetic. Oxford: Basil Blackwell, 1990.

ELSTER, Jon. Making Sense of Marx. Cambridge: Cambridge University Press, 1985.

GIDDENS, Anthony. Central Problems in Social Theory. Berkeley: Cambridge University Press, 1979.

GRAMSCI, Antonio. Selections from the Prison Notebooks. Translate: Quintin Hoare \& Geoffrey Nowell Smith. New York: International Publishers, 1977.

HABERMAS, Jurgen. What Does Socialism Mean Today. In: BLACKBURN, Robin (Ed.). After the Fall: The Failure of Communism and the Future of Socialism. London: Verso, 1991.

HUBER, Peter. Cyberpower. Forbes, 2 dez. 1996, p. 142-147.

INNIS, Harold A. The Bias of Communication. Toronto: University of Toronto Press, 1951. 
JAMESON, Fredric. Wyndham Lewis: The Modernist as Fascist. Berkeley: University of California Press, 1979.

LUCAITES, John Louis; CONDIT, Celeste Michelle. Reconstructing "equality": Culturetypal and counter-cultural Rhetorics in the martyred black vision, Communication Monographs, n. 57, p. 5-24, 1990.

MARX, Karl; ENGELS, Friedrich. The German Ideology. Collected Works, vol. 5. New York: International Publishers, 1975.

MCGEE, Michael Calvin. Search of 'the People': A Rhetorical Alternative. Quarterly Journal of Speech, n. 61, v. 3, p. 235-248, 1975.

PICCONE, Paul. Italian Marxism. Berkeley: University of California Press, 1983.

POSNER, Richard. Sex and Reason. Cambridge: Harvard University Press, 1992.

WANDER, Philip. The Third Persona. An ideological turn in rhetorical theory. Central States Speech Journal, v. 35, p. 197-216, 2009 [1984].

WRIGHT, Erik Olin. Classes. London: Verso, 1985.

\section{Tradução}

Eduardo Lopes Piris

Docente da Universidade Estadual de Santa Cruz (UESC), Brasil

Paulo Roberto Gonçalves-Segundo

Docente da Universidade de São Paulo (USP), Brasil

\section{Forma de citação sugerida}

AUNE, James Arnt. Uma teoria histórico-materialista da retórica. Tradução: Eduardo Lopes Piris e Paulo Roberto Gonçalves-Segundo. EID\&A - Revista Eletrônica de Estudos Integrados em Discurso e Argumentação, Ilhéus, n. 19, v. 2, p. 185-207, dez.2019. DOI 10.17648/eidea-19-v2-2587. 